\begin{tabular}{ccc}
\hline International Journal of Engineering \& Technology, 7 (2.31) (2018) 249-251 & International Journal of Engineering \& Technology \\
SPC & Website: www.sciencepubco.com/index.php/IJET \\
Research paper & T \\
\hline
\end{tabular}

\title{
Stability Analysis of Networked Control System Using LMI Approach
}

\author{
Richa Sharma ${ }^{1 *}$, Deepak Nagaria ${ }^{2}$ \\ ${ }^{1}$ Research Scholar, A.K.T.U, Lucknow, India. \\ ${ }^{2}$ Associate Professor, A.K.T.U, Lucknow, India. \\ E-mail:deepaknagaria@gmail.com \\ *Corresponding author E-mail:s.richa.sharma@gmail.com
}

\begin{abstract}
Networked control system is a closed loop system in which information or data travel through the communication network. The presence of communication network will increase time delay and information losses. Due to these losses and delay the performance of the system decreases. This paper represents an analysis to find the stability of the networked control system with the varying time hindrances present in the network. In this research, it has been assumed that the delay in time is less than the sampling period. The stability conditions for NCS have been procured with the use of the Lyapunov function approach and has been described in terms of LMI(Linear Matrix Inequality).This examination confirm the adequate state of stability through MATLAB simulation and the numerical case demonstrates the outcome.
\end{abstract}

Keywords: Networked control system, Time delay, LMI, stability.

\section{Introduction}

As of late, networked control system have gotten much consideration because of a few preferences brought by arrange presentation, for example, expanded framework adaptability, simplicity of upkeep bring down cost. Networked control systems are a closed loop systems whither control system components (plant, sensor, actuator and controller) communicated through real time network. Accordingly, arranged control system have been broadly connected to many convoluted control systems, for example, producing plants, vehicles, flying machine, and spacecraft.

Be that as it may, by virtue of addition of communication network, time delay is continuously unavoidable, and the presence of delay in time, on other hand, may debilitate the impact and effectiveness of control systems, and then again, it might even prompt the instability of the control systems [1,2]. This time delay might be constant, time varying and random in nature. If time suspension is shorter than the sampling period it is known as short time delay and if the suspension greater than the sampling period then it is referred to as longer time delay [3].

It is realized that the presence of the time hindrances corrupts the steadiness and regulates execution of the closed loop control system. The focus on the stability, controller plan for adjustment and execution accomplishment schemes have been laid by numerous scientists for the networked control system along with the induced delay. In [4] proposed a performance investigation of a particular networked control system along with time-delay. In [5], utilize imbalance procedure to increase the LyapunovKrasovskii functional, and find proper condition in view of the linear matrix inequality.

In [6], derived stability condition in terms of LMI when time varying interval and time delay was considered in networked control system. In [7] proposed a Lyapunov-Krasovskii functional based stability criteria. In [8],synthesized the controller problem in networked control system with the existence of packet dropout and the varying delays. In [9], employed switched Lyapunov functional method for system model. In this paper time delay and sampling period are transformed to polytypic and norm-bounded uncertainties of the system.

In this paper, we examine the stability issue of networked system. By using a suitable Lyapunov-Krasovskii functional. An adequate stability condition of closed system is presented in form of Linear Matrix Inequalities (LMIs).This paper is sorted out as takes after: In segment ii we exhibit the problem formulation. Segment-iii presents the stability conditions with networked induced delay. Simulation of the system is presented in segment- iv. The summary of the paper is presented in segment-v.

\section{Problem Formulation}

Consider the plant model [10] stated below,

$\dot{\mathbf{x}}(\mathrm{t})=\mathrm{A}^{\mathrm{p}} \mathrm{x}(\mathrm{t})+\mathrm{B}^{\mathrm{p}} \mathrm{u}(\mathrm{t})$

$y(t)=C^{p} x(t)$

Here state vector is represented by $x(t) \in R$, control input is resented by $\mathrm{u}(\mathrm{t})$ and $\mathrm{y}(\mathrm{t})$ is plant output $\epsilon \mathrm{R}, \mathrm{A}^{\mathrm{p}}, \mathrm{B}^{\mathrm{p}}, \mathrm{C}^{\mathrm{p}}$ constant matrices with appropriate size.

Discrete time representation of equation (1) with sampling period $\mathrm{T}$

$\mathrm{x}(\mathrm{k}+1)=\mathrm{A}_{\mathrm{d}} \mathrm{x}(\mathrm{k})+\mathrm{B}_{\mathrm{d}} \mathrm{u}(\mathrm{k})$

$\mathrm{y}(\mathrm{k})=\mathrm{C}_{\mathrm{d}} \mathrm{x}(\mathrm{k})$

Where $\mathrm{A}_{\mathrm{d}=} e^{A p T}, \mathrm{~B}_{\mathrm{d}=} \int_{0}^{T} e^{A p t} \mathrm{~B}^{\mathrm{p}} \mathrm{dt}$ 
The controller information are transmitted to the plant over communication channel so time delay is inescapable to be associated with the closed loop. The state of response controller that is the feedback can be described as

$\mathrm{u}(\mathrm{k})=\mathrm{Fx}(\mathrm{k})$

Where $\mathrm{F}$ is the controller gain. Figure 1 clearly shows the position of communication network.

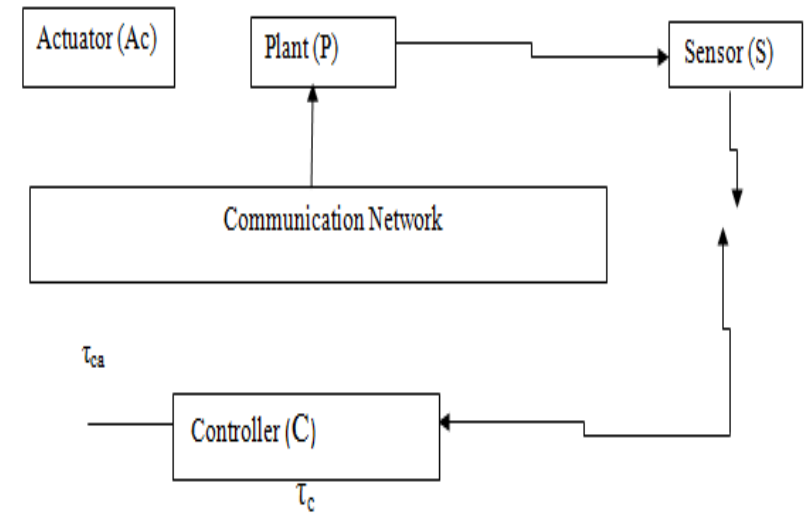

Fig. 1: Networked control system

Assume that the delay between ' $\mathrm{S}$ ' to ' $\mathrm{C}$ ' is $\tau_{\mathrm{sc}}$ and ' $\mathrm{C}$ ' to 'Ac' is $\tau_{\mathrm{ca}}$ and the processing time of the controller is $\tau_{\mathrm{c}}[11]$ as shown in figure 1 .

Total time delay of the system $\tau_{\mathrm{k}}=\tau_{\mathrm{ca}+} \tau_{\mathrm{sc}+} \tau_{\mathrm{c} \text {. }}$

So state response signal is:

$\mathrm{u}(\mathrm{k})=\mathrm{Fx}\left(\mathrm{k}-\tau_{\mathrm{k}}\right)$

This delay can be persistent, erratic or arbitrary in nature. Applying feedback to system (2) we find

$\mathrm{x}(\mathrm{k}+1)=\mathrm{A}_{\mathrm{d}} \mathrm{x}(\mathrm{k})+\mathrm{B}_{\mathrm{d}} \mathrm{Fx}\left(\mathrm{k}-\tau_{\mathrm{k}}\right)$

From (5) can be derived as:

$x(k+1)=\left(A_{d}+B_{d} F\right) x(k)+B_{d} F\left[x\left(k-\tau_{k}\right)-x(k)\right]$

Since the network time delay is bounded we assume that delay is limited as

$\tau_{\mathrm{k}}(\min ) \leq \tau_{\mathrm{k}}<\tau_{\mathrm{k}}(\max )$

It is clearly visible that the system (5) is a fluctuating discrete-time system with dual time-varying postponements. The target of the paper is to derive some dependability conditions for closed system in terms of LMI.

\section{Stability Conditions with Network Induced Delay}

In this section, few stability hypotheses are exhibited to take care of the issue of the organized networked system in (5).

Theorem 1:System(2)with the response control of (3), the closedloop system is asymptotically steady if

$\operatorname{\Lambda i}(\Phi) € \mathrm{C}^{-} \quad$ for $\mathrm{i}=1,2,3,4 \ldots \ldots \ldots .$.

where $\Phi=\left[\left(I+\tau B_{d} F\right)^{-1}\left(A_{d}+B_{d} F\right)\right]$

$\mathrm{x}\left(\mathrm{k}-\tau_{\mathrm{k}}\right)$ can be obtained by Taylor expansion if time delay is small $\mathrm{x}\left(\mathrm{k}-\tau_{\mathrm{k}}\right) \approx \mathrm{x}(\mathrm{k})-\tau \mathrm{x}(\mathrm{k}+1)$

$\tau \mathrm{x}(\mathrm{k}+1) \approx \mathrm{x}(\mathrm{k})-\mathrm{x}\left(\mathrm{k}-\tau_{\mathrm{k}}\right)$
Substitute (9) into (6)

$\mathrm{x}(\mathrm{k}+1)=\left(\mathrm{A}_{\mathrm{d}}+\mathrm{B}_{\mathrm{d}} \mathrm{F}\right) \mathrm{x}(\mathrm{k})-\mathrm{B}_{\mathrm{d}} \mathrm{F} \tau \mathrm{x}(\mathrm{k}+1)$

$\mathrm{x}(\mathrm{k}+1)\left(\mathrm{I}+\mathrm{B}_{\mathrm{d}} \mathrm{F} \tau\right)=\left(\mathrm{A}_{\mathrm{d}}+\mathrm{B}_{\mathrm{d}} \mathrm{F}\right) \mathrm{x}(\mathrm{k})$

$\mathrm{x}(\mathrm{k}+1)=\left[\left(\mathrm{I}+\mathrm{B}_{\mathrm{d}} \mathrm{F} \tau\right)^{-1}\left(\mathrm{~A}_{\mathrm{d}}+\mathrm{B}_{\mathrm{d}} \mathrm{F}\right)\right] \mathrm{x}(\mathrm{k})$

The equation (10) will be asymptotically stable if Ki $(\Phi) \in \mathrm{C}^{-}$

The Lyapunov equation can be defined as

$\left(\mathrm{A}_{\mathrm{d}}+\mathrm{B}_{\mathrm{d}} \mathrm{F}\right)^{\mathrm{T}} \mathrm{P}+\left(\mathrm{A}_{\mathrm{d}}+\mathrm{B}_{\mathrm{d}} \mathrm{F}\right) \mathrm{P}=-\mathrm{Q}$

Where $\mathrm{Q}$ is define as positive-definite matrix.

Choose a Lyapunov functional for thesystem [12]

$\mathrm{V}(\mathrm{x})=\mathrm{x}^{\mathrm{T}} \mathrm{Px}$

Where $\mathrm{P}$ is a positive definite matrix.

$\mathrm{x}\left(\mathrm{k}-\tau_{\mathrm{k}}\right)=\mathrm{x}(\mathrm{k})-\int_{-\tau}^{0} \dot{\mathrm{x}}(\mathrm{k}+\theta) d \theta$

$=\mathrm{x}(\mathrm{k})-\int_{-\tau}^{0}[\operatorname{Adx}(\mathrm{k})+\mathrm{Bd} \mathrm{Fx}(\mathrm{k}-\tau \mathrm{k}+\theta) d \theta$

The derivative of (11)

$\mathrm{V}^{*}(\mathrm{x})=\mathrm{x}^{\mathrm{T}} \mathrm{P} \dot{\mathrm{x}}+\dot{\mathrm{x}}^{\mathrm{T}} \mathrm{P} \mathrm{x}$

$=x^{T}(k) P\left(A_{d} x(k)+B_{d} F x\left(k-\tau_{k}\right)\right)+\left[A_{d} x(k)+B_{d} F x\left(k-\tau_{k}\right)\right]^{T} P$ $\mathrm{x}(\mathrm{k})$

$=\mathrm{x}^{\mathrm{T}}(\mathrm{k}) \mathrm{P}\left(\mathrm{A}_{\mathrm{d}} \mathrm{x}(\mathrm{k})+\mathrm{B}_{\mathrm{d}} \mathrm{F}\left(\mathrm{x}(\mathrm{k})-\int_{-\tau}^{0}[\mathrm{Adx}(\mathrm{k})+\mathrm{Bd} \mathrm{Fx}(\mathrm{k}-\tau \mathrm{k}+\right.\right.$

$\theta) d \theta)+\left[\mathrm{x}(\mathrm{k})-\int_{-\tau}^{0}[\mathrm{Adx}(\mathrm{k})+\mathrm{Bd} \mathrm{Fx}(\mathrm{k}-\tau \mathrm{k}+\theta) d \theta]^{\mathrm{T}} \mathrm{P} \mathrm{x}(\mathrm{k})\right.$ $=\mathrm{x}^{\mathrm{T}}(\mathrm{k}) \mathrm{P}\left(\mathrm{A}_{\mathrm{d}} \mathrm{x}(\mathrm{k})+\mathrm{B}_{\mathrm{d}} \mathrm{Fx}(\mathrm{k})-\right.$ $\left.\mathrm{Bd} \mathrm{F} \int_{-\tau}^{0}[\mathrm{Adx}(\mathrm{k})+\mathrm{BdFx}(\mathrm{k}-\tau \mathrm{k}+\theta)] d \theta\right)$ $+\left[\mathrm{x}(\mathrm{k})-\int_{-\tau}^{0}[\operatorname{Adx}(\mathrm{k})+\operatorname{Bd~Fx}(\mathrm{k}-\tau \mathrm{k}+\theta) d \theta\right.$ ]$^{\mathrm{T}} \mathrm{P} x(\mathrm{k})$

$=-x^{T}(k) Q x(k)+\| x^{T}(k)\left(P\left(A_{d+} B_{d} F\right)+\left(A_{d+} B_{d} F\right)^{T} P\right)+2$

$\left.\int_{-\tau}^{0} \mathrm{xT}(\mathrm{k}) \mathrm{BdF} \operatorname{Adx}(\mathrm{k}+\theta)+\operatorname{BdFx}(\mathrm{k}-\tau \mathrm{k}+\theta)\right] d \theta \|$

According to Razumikhin-type theorem we can calculate $\mathrm{V}^{*}(\mathrm{x})$ for

$\mathrm{V}(\mathrm{x}(\theta))<\delta \mathrm{V}(\mathrm{x}(\mathrm{t}))$

Where $\delta>1$.

Hence $\mathrm{V}^{\cdot}(\mathrm{x})<0$ for $\mathrm{V}(\mathrm{x}(\theta))<\delta \mathrm{V}(\mathrm{x}(\mathrm{t}))$ if

$\mathrm{P}\left(\mathrm{A}_{\mathrm{d}+} \mathrm{B}_{\mathrm{d}} \mathrm{F}\right)+\left(\mathrm{A}_{\mathrm{d}+} \mathrm{B}_{\mathrm{d}} \mathrm{F}\right)^{\mathrm{T}} \mathrm{P}+\tau\left(2 \mathrm{P}+\mathrm{PBQB}{ }^{\mathrm{T}} \mathrm{P}\right)<0(15)$

System (2) is asymptotically stable if equation (14) is satisfied.

\section{Simulation}

Considering the plant model [13]

System matrix

$$
\dot{x}(t)=\left[\begin{array}{cc}
-2 & 0 \\
1 & -3
\end{array}\right] x(t)+\left[\begin{array}{cc}
-1.4 & 0 \\
-0.8 & -1.5
\end{array}\right] \mathrm{u}(\mathrm{t})
$$

$$
\mathrm{A}=\left[\begin{array}{cc}
-2 & 0 \\
1 & -3
\end{array}\right] \quad \mathrm{B}=\left[\begin{array}{cc}
-1.4 & 0 \\
-0.8 & -1.5
\end{array}\right]
$$

When sampling period is $0.3 \mathrm{sec}$ the discretized plant model

$$
\begin{aligned}
& \mathrm{A}_{\mathrm{d}}=\left[\begin{array}{cc}
0.5488 & 1 \\
1.349 & 0.4066
\end{array}\right] \\
& \mathrm{B}_{\mathrm{d}}=\left[\begin{array}{cc}
2.1055 & 0 \\
-0.0502 & 2.967
\end{array}\right]
\end{aligned}
$$

Eigenvalues of $\mathrm{A}_{d}, \mathrm{~A}_{d}=\left[\begin{array}{ll}1.6417 & -0.6863\end{array}\right]$ 


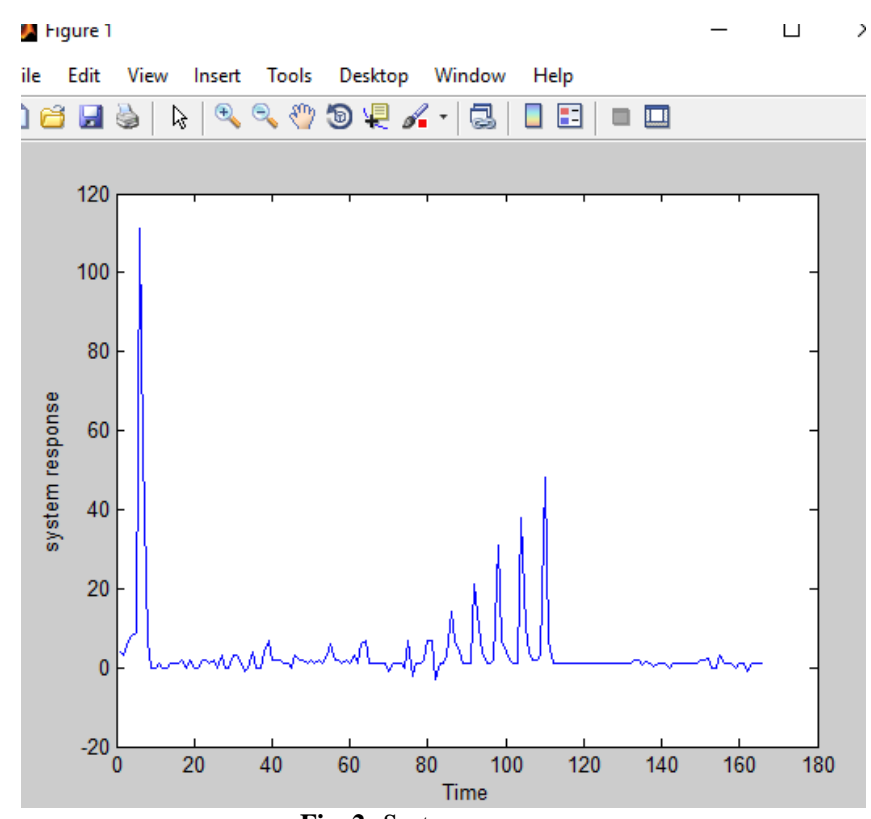

Fig. 2: System response

Fig. 2 represent the state system response using LMI [14]. By using LMI toolbox we can calculate feedback controller gain which make system asymptotically stable. Controller gain stabilizes the closed system

$$
\mathrm{F}=\left[\begin{array}{cc}
0.1388 & -0.1270 \\
-0.1751 & 0.1603
\end{array}\right]
$$

Feedback controller state with initial states $\mathrm{x}_{0}=[-1,1]$

$$
\mathrm{u}(\mathrm{k})=\left[\begin{array}{cc}
0.1388 & -0.1270 \\
-0.1751 & 0.1603
\end{array}\right] \mathrm{x}\left(\mathrm{k}-\tau_{\mathrm{k}}\right)
$$

Figure 3 indicates the system performance with initial condition and time delay $0 \mathrm{sec}$. Using LMI tool box positive definite matrix value is

$$
P=\left[\begin{array}{cc}
249.6 & -228.4 \\
-228.4 & 209.01
\end{array}\right]
$$

Controller gain when time delay is $0.1 \mathrm{sec}$

$$
\begin{aligned}
& \mathrm{F}=\left[\begin{array}{cc}
0.2784 & -0.2549 \\
-0.1507 & 0.1380
\end{array}\right] \\
& \mathrm{P}=\left[\begin{array}{cc}
749.13 & -685.67 \\
-685.67 & 627.59
\end{array}\right]
\end{aligned}
$$

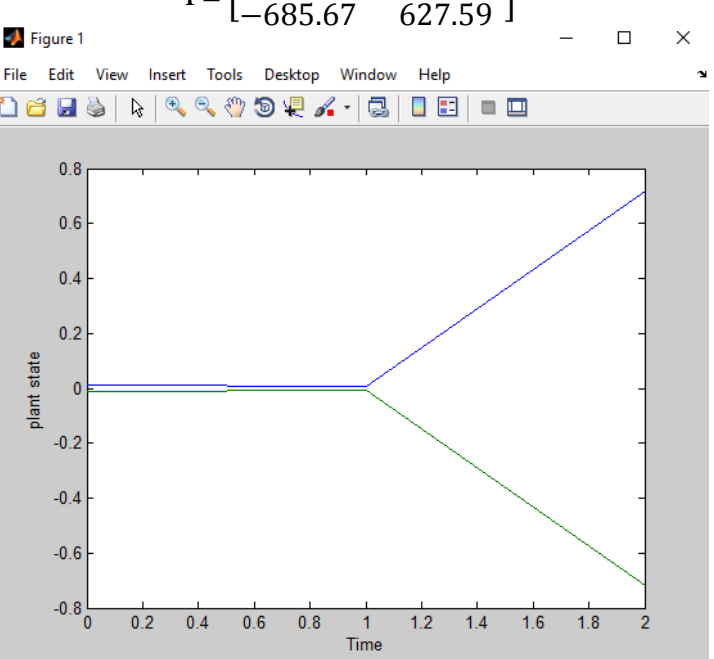

Fig. 3: Performance of the system

\section{Conclusion}

We have examined the stabilization issue for networked control systems along with the transmission suspensions actuated by organizing channels. The acceptable higher bound of transmission delays can be gotten LMI tool box. The feedback controllers can be built regarding LMIs. The most appealing element of this technique is that it is a straightforward approach and simple to be connected, which can be effortlessly translated to configuration builds in modern industrial. Numerical illustrations have been given to exhibit the viability of the proposed stability paradigm.

\section{References}

[1] Shenping X, Lixin G \& Liyan W, "The Stability Analysis for a Class of Time-Delay Networked Control Systems", Chinese Control and Decision Conference, (2014)

[2] Jian S \& Jie C, "Stability analysis of networked control systems with aperiodic sampling", Chinese Control Conference, (2013).

[3] Yang R, Shi P, Liu G \& Gao H, "Network-based feedback control for systems with mixed delays based on quantization and dropout compensation", Automatica, Vol.47, No.12, (2011), pp.2805-2809,

[4] Du ZP, Zhang QL \& Liu LL, "Stability of singular networked control system with delay and data packet dropout", Journal of Northeastern University, Vol.30, No.1, (2009), pp.17-20.

[5] Park M, Kwon O, Park J, Lee S, "Delay-dependent Stability Criteria for Linear Time-delay System of Neutral Type", World Academy of Engineering and Technology, (2010).

[6] Donkers M, Heemels W, Van de Wouw N \& Hetel L, "Stability analysis of networked control systems using a switched linear systems approach", IEEE Transactions on Automatic Control, Vol.56, No.9, (2011), pp.2101-2115.

[7] Tang B, Liu GP \& Gui WH, "Improvement of state feedback controller design for networked control systems", IEEE Transactions on Circuits and Systems, Vol.55, No.5, (2008), pp.464-468.

[8] Cloosterman MBG, Hetel L, Van De Wouw N, Heemels W, Daafouz J \& Nijmeijer H, "Controller synthesis for networked control systems", Automatica, Vol.46, No.10, (2010), pp.1584-1594.

[9] Izak M, Gorges D \& Liu S, "Stabilization of systems with variable and uncertain period and time delay", Nonlinear Analysis: Hybrid Systems, Vol.4, No.2, (2010), pp.291-305.

[10] Zhicheng L, Fuad A,Tasawar H \& Huijun G, "New results on stability analysis and stabilisation of networked control system", IET Control Theory Appl., Vol.8, (2014), pp.1707-1715.

[11] Fatemeh K, Mohsen E \& Mohammad A, "Stability analysis of networked control systems with time varying delays", Iranian Conference on Electrical Engineering, (2017).

[12] Ashraf FK \& Jihong W, "Stability and Time Delay Tolerance Analysis Approach for Networked Control Systems", Mathematical Problems in Engineering, (2015).

[13] Xun LZ \& Guang HY, "New Results on Stability Analysis of Networked Control Systems", American Control Conference, (2008).

[14] Boyd S, El Ghaoui L, Feron E \& Balakrishnan V, "Linear Matrix Inequalities in Systems and Control Theory", SIAM Frontier Series, (1994).

[15] Katsuhiko O, Modern Control Engineering, Third Edition, Prentice Hall, (1997) 